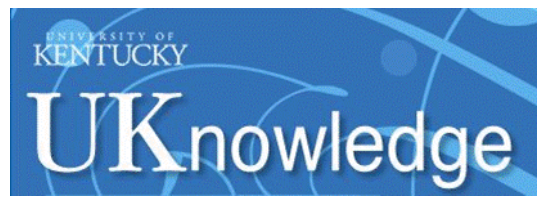

University of Kentucky

UKnowledge

\title{
Modeling and Control of a Multiport Converter Based EV Charging Station with PV and Battery
}

Yibin Zhang

University of Kentucky, yibin.zhang@uky.edu

Jiangbiao $\mathrm{He}$

University of Kentucky, Jiangbiao.He@uky.edu

Dan M. Ionel

University of Kentucky, dan.ionel@uky.edu

Follow this and additional works at: https://uknowledge.uky.edu/peik_facpub

Part of the Power and Energy Commons

Right click to open a feedback form in a new tab to let us know how this document benefits you.

\section{Repository Citation}

Zhang, Yibin; He, Jiangbiao; and Ionel, Dan M., "Modeling and Control of a Multiport Converter Based EV Charging Station with PV and Battery" (2019). Power and Energy Institute of Kentucky Faculty

Publications. 21.

https://uknowledge.uky.edu/peik_facpub/21

This Conference Proceeding is brought to you for free and open access by the Power and Energy Institute of Kentucky at UKnowledge. It has been accepted for inclusion in Power and Energy Institute of Kentucky Faculty Publications by an authorized administrator of UKnowledge. For more information, please contact UKnowledge@lsv.uky.edu. 


\title{
Modeling and Control of a Multiport Converter Based EV Charging Station with PV and Battery
}

\author{
Digital Object Identifier (DOI) \\ https://doi.org/10.1109/ITEC.2019.8790632
}

\section{Notes/Citation Information}

Published in 2019 IEEE Transportation Electrification Conference and Expo (ITEC).

(C) 2019 IEEE Copyright Notice. "Personal use of this material is permitted. Permission from IEEE must be obtained for all other uses, in any currentor future media, including reprinting/republishing this material for advertising or promotional purposes, creating new collective works, for resale or redistribution to servers or lists,or reuse of any copyrighted component of this work in other works."

The document available for download is the authors' manuscript version that is accepted for publication. The final published version is copyrighted by IEEE and is available as: Y. Zhang, J. He, and D. M. Ionel, "Modeling and Control of a Multiport Converter based EV Charging Station with PV and Battery," 2019 IEEE Transportation Electrification Conference and Expo (ITEC), Novi, MI, June 2019, pp. 1-5, doi:10.1109/ ITEC.2019.8790632 


\title{
Modeling and Control of a Multiport Converter based EV Charging Station with PV and Battery
}

\author{
Yibin Zhang, Student Member, IEEE, Jiangbiao He, Senior Member, IEEE, and Dan M. Ionel, Fellow IEEE \\ SPARK Lab, Department of Electrical and Computer Engineering \\ University of Kentucky, Lexington, KY, USA \\ yibin.zhang@uky.edu, jiangbiao.he@uky.edu,dan.ionel@uky.edu
}

\begin{abstract}
As an environmental friendly vehicle, the increasing number of electrical vehicles (EVs) leads to a pressing need of widely distributed charging stations, especially due to the limited on-board battery capacity. However, fast charging stations, especially super-fast charging stations may stress power grid with potential overload at peaking time, sudden power gap and voltage sag. This paper discusses the detailed modeling of a multiport converter based EV charging station integrated with PV power generation, and battery energy storage system, by using ANSYS TwinBuilder. In this paper, the control scheme and combination of $P V$ power generation, $\mathrm{EV}$ charging station, and battery energy storage (BES) provides improved stabilization including power gap balancing, peak shaving and valley filling, and voltage sag compensation. As a result, the influence on power grid is reduced due to the matching between daily charging demand and adequate daytime PV generation. Simulation results are presented to confirm the benefits at different modes of this proposed multiport EV charging circuits with the PV-BES configuration. Furthermore, $\mathrm{SiC}$ devices are employed to the $\mathrm{EV}$ charging station to further improve the efficiency. For different modes and functions, power losses and efficiency are investigated and compared in simulation with conventional Si devices based charging circuits.
\end{abstract}

Index Terms - EV charging station, PV, BES, power gap balancing, voltage sag compensation.

\section{INTRODUCTION}

With the growing interest in decreasing the fossil fuel utilization and pollution, electric vehicles (EVs) have emerged as an applicable alternative to conventional gas engine vehicles [1]. The development and increasing utilization of EVs requires widely distributed charging stations due to the limited EV battery capacity [2]. However, large scale of directly grid-connected charging stations, especially fast and superfast charging stations, stress power grid stability and reliability with peak demand overload, voltage sag, and power gap issues [3]. Some researchers have been integrating photovoltaic (PV) generation with EV charging infrastructure [4]; however, the $\mathrm{PV}$ integration is still considered as a minor portion of power source for EV charging stations in researches. As for the higher demand of fast-speed charging during daytime, the rapid development of PV generation optimizes power consumption at peak hours with its adequate daytime generations. With respect to the intermittency of solar energy, a battery energy storage (BES) can be employed to regulate the DC bus or load voltage, balance power gap, and smooth PV power [5].

Considering the high power density and high efficiency merits of the multiport power converters [6], a multiport DC/DC converter is employed in this paper for the EV charging station instead of using three separate DC/DC converters. Among the aforementioned research, the charging station architectures can be classified into two topologies: using AC bus or DC bus [7]. As PV output and BES can both be regarded as DC current source [8], DC bus charging station is chosen here to improve the utilization efficiency of solar energy and decrease the cost and losses of converters. Compared with isolated multiport converters, nonisolated multiport converters that are usually derived from buck or boost converters may feature a more compact design, higher power density, and higher efficiency compared with isolated multiport converters [9] [10]. Accordingly, a DC bus nonisolated structure with $\mathrm{SiC}$ switches is leveraged in this paper, to improve efficiency and minimize the power losses. To sum up, the works and contributions in this paper can be summarized as follows. First, the PV and BES integration, rather than the power grid, is considered as a predominant power supply for EV charging. Then, detailed operating modes, control scheme, and the interaction among PV, BES, power grid, and EV charging are developed and investigated, in a scenario of high penetration of $\mathrm{PV}$ integration and widely spread $\mathrm{EV}$ charging infrastructures. Additionally, detailed power losses and efficiency comparison is investigated.

The remainder content of this paper is organized as follows. In Section II, the charging station architecture is proposed. Then the workflows between different power sources, and control designs including mathematical modeling, modulation, and power balance will be introduced. In Section III, the proposed control scheme for different modes is presented. Then the simulation results, power losses and efficiency comparison between $\mathrm{Si}$ and $\mathrm{SiC} \mathrm{EV}$ stations will be presented. Finally, conclusions will be given in Section IV.

\section{SySTEMATIC MODELING AND OPERATING PRINCIPLE}

In the conventional architecture of DC bus charging station with PV integration (Fig. 1a), all the three power sources, including PV and EV charger unidirectional sources, and AC grid bi-directional source, are all connected through three separate converters. The proposed DC bus charging station (Fig. 1b), consists of one more bi-directional power source BES sharing the same DC bus. The BES is utilized to maintain the DC link voltage and balance power surplus/insufficiency 


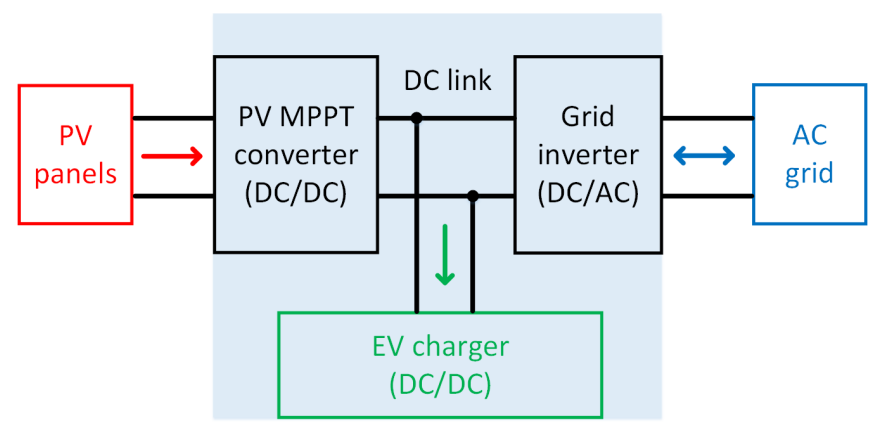

(a)

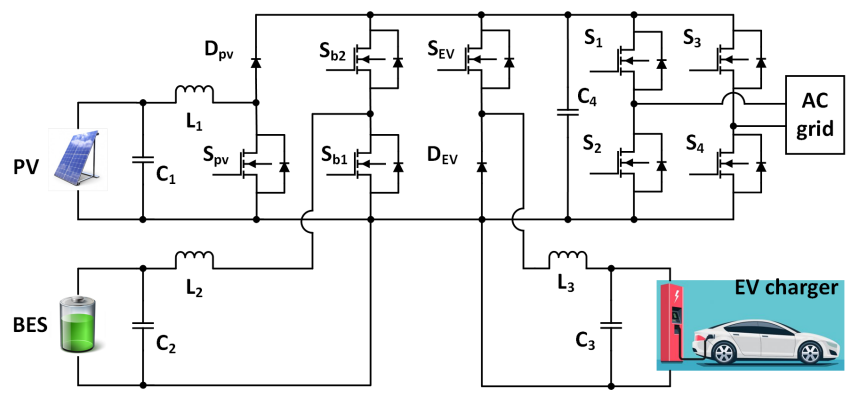

(b)

Figure 1. Multiport converter architectures, (a) the conventional architecture of EV charging stations integrated with $\mathrm{PV}$, and (b) the proposed multiport converter based EV charging station architecture integrated with PV and BES.

from the PV (Fig. 4). With this configuration, the function and operating modes can be discussed as follows in detail.

\section{A. Mode 1: PV to EV}

In this mode, the switches $S_{p v}, S_{b 1}$, and $S_{b 2}$ are turned off while $S_{E V}$ is turned on (Fig. 2a). Therefore, PV directly delivers power to the load, as shown in Fig. 2a. The differential equations in this stage can be expressed as follows:

$$
\begin{gathered}
i_{P V}=C_{1} \frac{d v_{C 1}}{d t}+i_{E V} \\
C_{2} \frac{d v_{C 2}}{d t}=\frac{v_{B a t}-v_{C 2}}{r_{b}}-i_{L 2} \\
i_{E V}=C_{3} \frac{d v_{C 3}}{d t}+\frac{v_{E V}}{R_{E V}} \\
v_{C 1}-v_{C 3}=L_{3} \frac{i_{L 3}}{d t} \\
L_{2} \frac{i_{L 2}}{d t}=-v_{C 2}
\end{gathered}
$$

where $C_{1}, C_{2}, C_{3}, L_{1}, L_{2}, L_{3}$, and $r_{b}$ represent the capacitance of the PV port capacitor, the capacitance of the BES port capacitor, the capacitance of the EV port capacitor, the inductance of the PV port inductor, the inductance of the BES port inductor, the inductance of the EV load port inductor, and the equivalent resistance between $v_{B a t}$ and $C_{2}$, respectively, as shown in Fig. $1 \mathrm{~b} ; i_{P V}, i_{E V}, i_{L 2}$, and $i_{L 3}$ represent the output current from PV panels, the current of EV load, the current through inductor $L_{2}$, and the current through inductor
$L_{3}$, respectively; $v_{C 1}, v_{C 2}, v_{C 3}, v_{B a t}$, and $v_{E V}$ represent the voltage across capacitor $C_{1}$, the voltage across $C_{2}$, the voltage across $C_{3}$, output voltage from BES, and the charger voltage, respectively. The duty cycle for the switch $S_{p v}$ can be obtained with:

$$
\frac{V_{D C}}{V_{P V}}=\frac{1}{1-D_{p v}}
$$

where $V_{D C}, V_{P V}$, and $D_{p v}$ represent the DC link voltage, voltage of PV array, and duty cycle of switch $S_{p v}$, respectively.

\section{B. Mode 2: BES to EV}

When $S_{p v}$ and $S_{E V}$ are turned on while $S_{b 1}$ and $S_{b 2}$ are turned off, BES is discharged to the EV load, as shown in Fig. 2b. The differential equations in this mode can be expressed as follows:

$$
\begin{gathered}
i_{P V}=C_{1} \frac{d v_{C 1}}{d t} \\
L_{2} \frac{i_{L 2}}{d t}=v_{D C}-v_{C 2} \\
v_{D C}-v_{C 3}=L_{3} \frac{i_{L_{3}}}{d t} \\
C_{2} \frac{d v_{C 2}}{d t}=\frac{v_{B a t}-v_{C 2}}{r_{b}}-i_{L 2} \\
i_{E V}=C_{3} \frac{d v_{C 3}}{d t}+\frac{v_{E V}}{R_{E V}}
\end{gathered}
$$

where $v_{D C}$ refers to DC link voltage, which equals to the voltage across capacitor $C_{4}$. The duty cycle for switch $S_{b 1}$ can be obtained with:

$$
\frac{V_{D C}}{V_{B a t}}=\frac{1}{1-D_{b 1}}
$$

where $V_{D C}, V_{B a t}$, and $D_{b 1}$ represent the DC link voltage, voltage of BES, and duty cycle of switch $S_{b 1}$, respectively.

\section{Mode 3: PV to BES}

When $S_{b 2}$ is turned on while $S_{b 1}, S_{p v}$ and $S_{E V}$ are turned off, BES is charged from the PV surplus energy, as shown in Fig. 2c. The differential equations in this mode can be expressed as follows:

$$
\begin{gathered}
i_{P V}=C_{1} \frac{d v_{C 1}}{d t}-i_{L 2} \\
L_{2} \frac{i_{L 2}}{d t}=v_{C 1}+v_{D C}-v_{C 2} \\
L_{3} \frac{i_{L 3}}{d t}=v_{D C}-v_{C 3} \\
C_{2} \frac{d v_{C 2}}{d t}=\frac{v_{B a t}-v_{C 2}}{r_{b}}-i_{L 2} \\
i_{E V}=C_{3} \frac{d v_{C 3}}{d t}+\frac{v_{E V}}{R_{E V}}
\end{gathered}
$$

The duty cycle for the switch $S_{b 2}$ can be obtained with: 


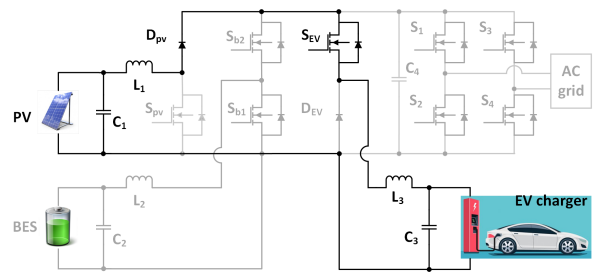

(a)

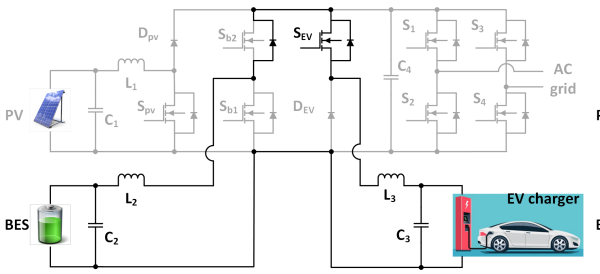

(b)

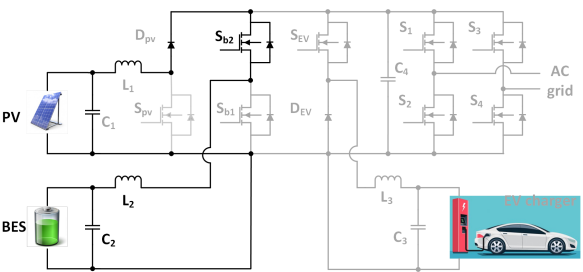

(c)

Figure 2. Multiport converter operating modes, (a) PV supplies EV charging when solar energy is sufficient, (b) BES supplies EV charging during PV intermittent, and (c) PV charges BES when solar generation is surplus.

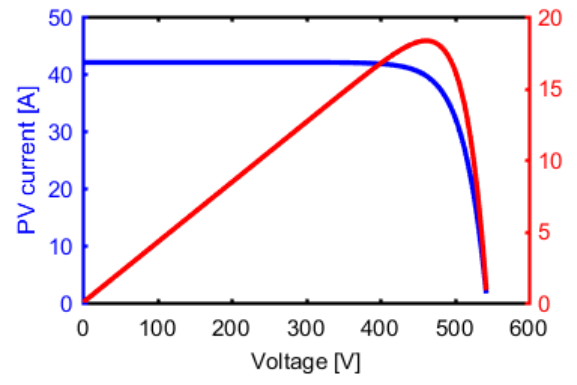

(a)

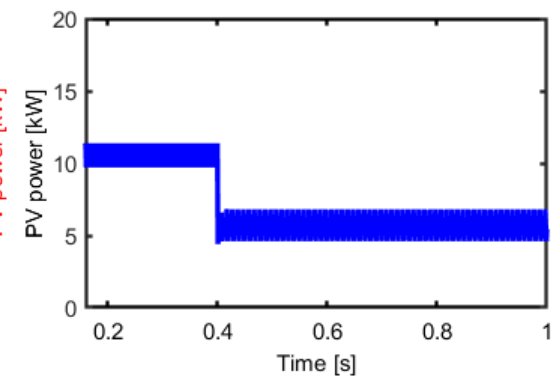

(b)

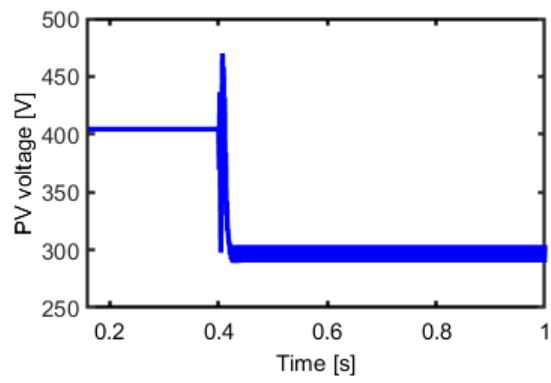

(c)

Figure 3. PV outputs when irradiance drops from 1000 to $500 \mathrm{~W} / \mathrm{m}^{2}$, (a) the I-V and P-V characteristics of the modeled PV panels, (b) the output power from the PV panels, and (c) the output voltage of the PV panels.

$$
\frac{V_{B a t}}{V_{D C}}=D_{b 2}
$$

where $D_{b 2}$ represents the duty cycle of the switch $S_{b 2}$.

\section{Other Modes: PV to BES, Grid to EV, and PV to Grid}

The operating principle of other modes including PV to $\mathrm{BES}$, grid to EV, and PV to grid, are summarized in Table I. Besides, the differential equations can be similarly expressed with the same analysis method in Modes 1 to 3 . The detailed simulation analysis will be provided in the following section.

Table I

THE EV CHARGING OPERATING MODES

\begin{tabular}{ccccc}
\hline \hline$S_{p v}$ & $S_{b 1}$ & $S_{b 2}$ & $S_{E V}$ & Power flow \\
\hline off & off & off & on & PV to EV \\
off & off & on & off & PV to BES \\
on & off & off & on & BES to EV \\
- & on/off & off/on & on & Grid to EV \\
off & off & off & off & PV to grid \\
\hline
\end{tabular}

\section{Simulation RESUlts}

To evaluate the proposed charging station functions and control schemes, a simulation model following the structure in Fig. 1b is established in ANSYS TwinBuilder. The PV array is modeled with Suntech STP235-20-Wd [11], with 14 strings in series and 5 strings in parallel. For the open circuit, the modeled PV array is able to supply $16 k \mathrm{~W} 500 \mathrm{~V}$ to feed the

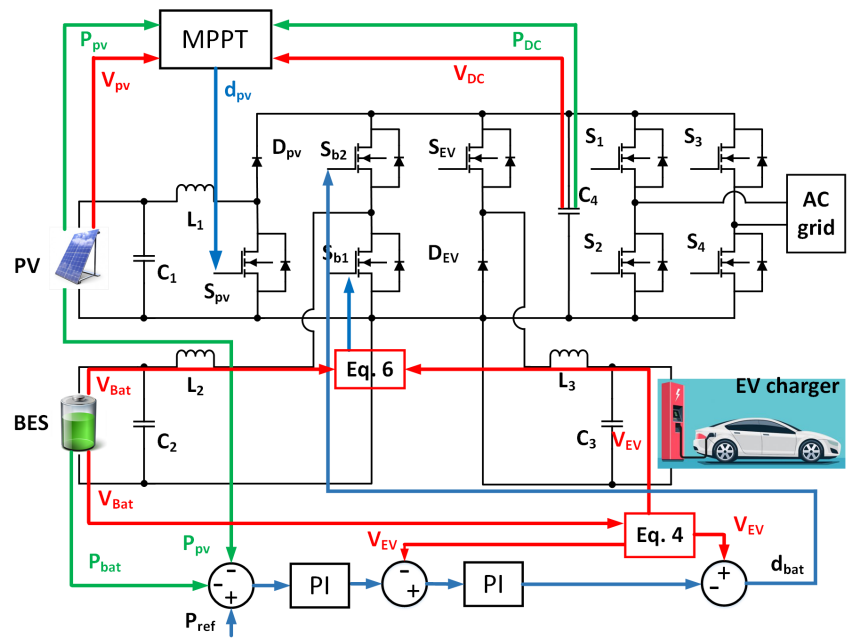

Figure 4. The block diagram for the BES controller and the PV controller with MPPT.

EV charger and a MPPT controller (Fig. 3a) is developed to extract the maximum power from PV panels while maintains a constant DC voltage.

For the BES controller, the objective is to regulate the power gap and support the load voltage (Fig. 4). When the solar is sufficient, EV charging is supplied from PV panels. If the PV generation is surplus, BES will be charged and consume locally. If PV is insufficient such as partial shading and other intermittent conditions, BES starts to discharge and fill in the power gap between PV and EV charging. 


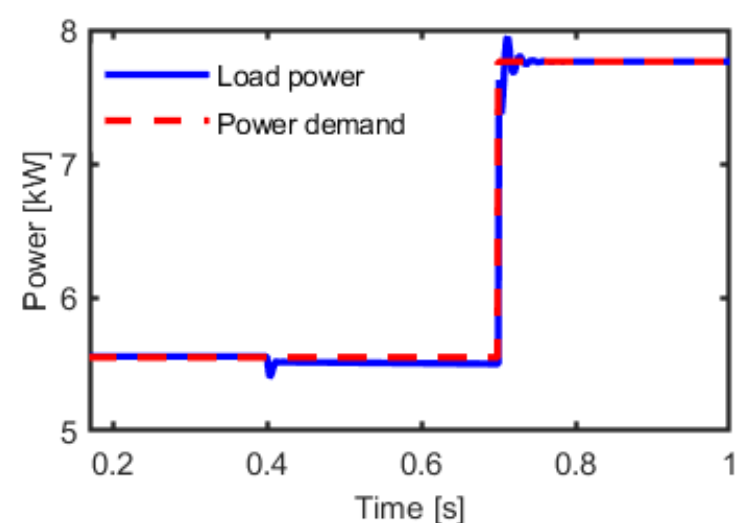

(a)

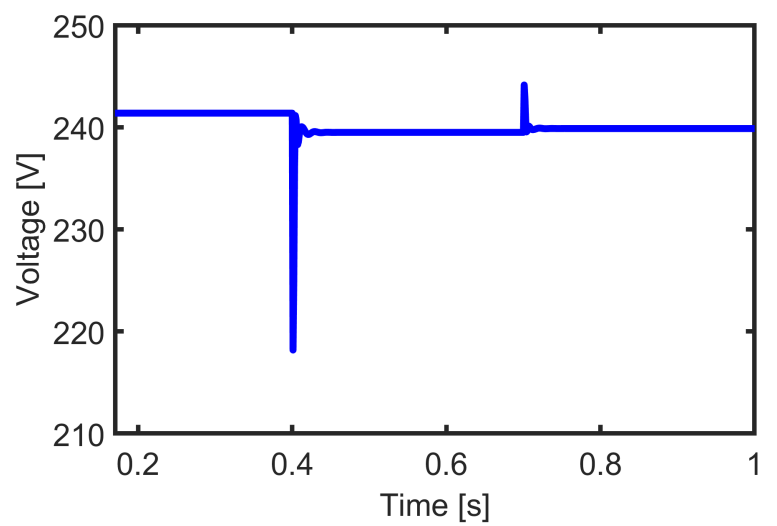

(b)

Figure 5. The simulation results of EV charging, (a) the demand and consumed power of EV charging, (b) the terminal voltage of the EV charger.

A case of this control scheme is simulated with ANSYS TwinBuilder. At $400 \mathrm{~ms}$ of the simulation time, the irradiance drops from $1000 k / W^{2}$ to $500 k / W^{2}$, and the output power of the PV panels drops from $11 \mathrm{~kW}$ to $5.7 \mathrm{~kW}$ at $425 \mathrm{~V}$ (Fig. 3 ), with the MPPT strategy implemented. At $700 \mathrm{~ms}$ of the simulation time, EV charging demand suddenly goes up from $5.7 \mathrm{~kW}$ to $7.7 \mathrm{~kW}$.

In this scenario, between the simulation time of 0 to $400 \mathrm{~ms}$, the EV charging demand is low while the PV generation is sufficient. Therefore, both PV-to-EV and PV-to-BES modes are triggered, and the surplus PV generation charges the BES. Between the simulation time of $400 \mathrm{~ms}$ to $700 \mathrm{~ms}$, the PV panels can provide $5.7 \mathrm{~kW}$ which meets the EV charging amount. As a result, the system is operated in PV-to-EV mode and no BES charging/discharging is required. After the charging demand increase at $700 \mathrm{~ms}$, the PV panels are not able to supply all the required $7.7 \mathrm{~kW}$ charging power under the condition of $500 k / W^{2}$ irradiance. Therefore, the BES starts to discharge and supply EV charging with $2 k W$ and provides voltage support, as shown in Fig. 6.

Additionally, to improve the efficiency and power density of the multiport converter, SiC MOSFETs (CREE 900V/36A C3M0065090D [12]) are utilized. The comparison of the

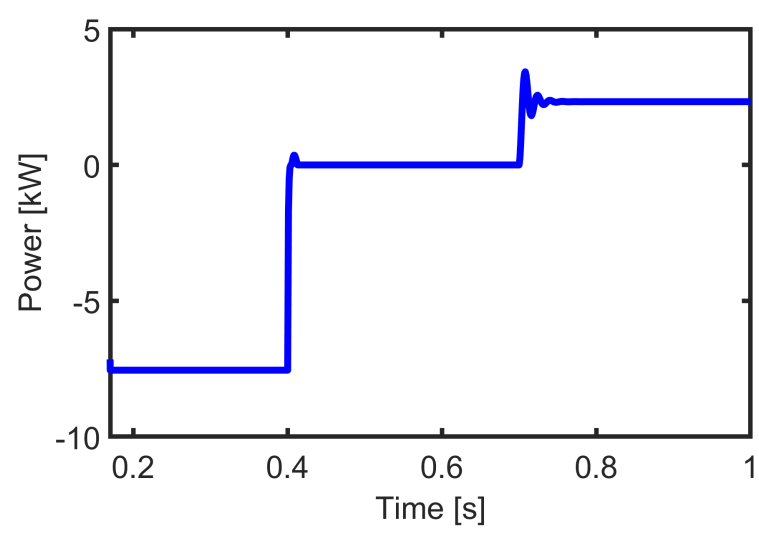

(a)

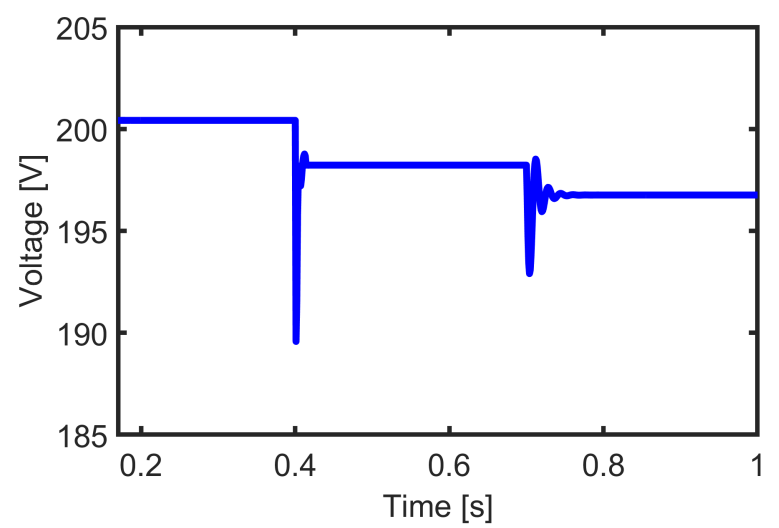

(b)

Figure 6. The simulation results of the BES, (a) the output power from BES, (b) the terminal voltage of the BES. conduction losses and switching losses in each semiconductor device for different operating modes at different load percentage is simulated, as shown in Fig. 7. It can be seen that both the conduction (Fig. 7a) and switching losses (Fig. 7b) are reduced in the proposed $\mathrm{SiC}$ based EV charging stations. Particularly, the switching loss of the conventional $\mathrm{Si}$ converters is much larger than the one in the proposed $\mathrm{SiC}$ counterparts. As a result, the efficiency comparison based on the simulated device losses are shown in Fig. 8. At nominal load condition, the proposed EV charging station has an efficiency of $98.41 \%$ for PV-to-EV mode, which is $5.67 \%$ higher than the conventional Si (Infineon 900V/36A IPW90R120C3 Si MOSFET [13]) based converter at the same condition. For PV-to-BES mode at nominal rating, the proposed $\mathrm{EV}$ charging station has an efficiency of $98.37 \%$, which is $4.46 \%$ higher than the conventional $\mathrm{Si}$ based converter under the same condition. Under the condition of the nominal rating of the BES-to-EV mode, the efficiency of the proposed charging station is $6.00 \%$ higher than the Si counterpart.

\section{CONCLUSIONS}

In this paper, a multiport converter based EV charging station with PV and BES is proposed. A BES controller is 


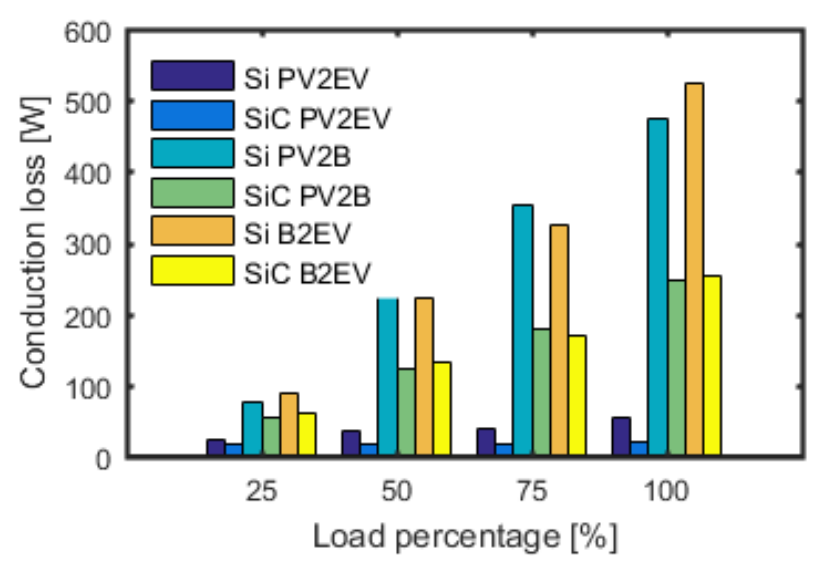

(a)

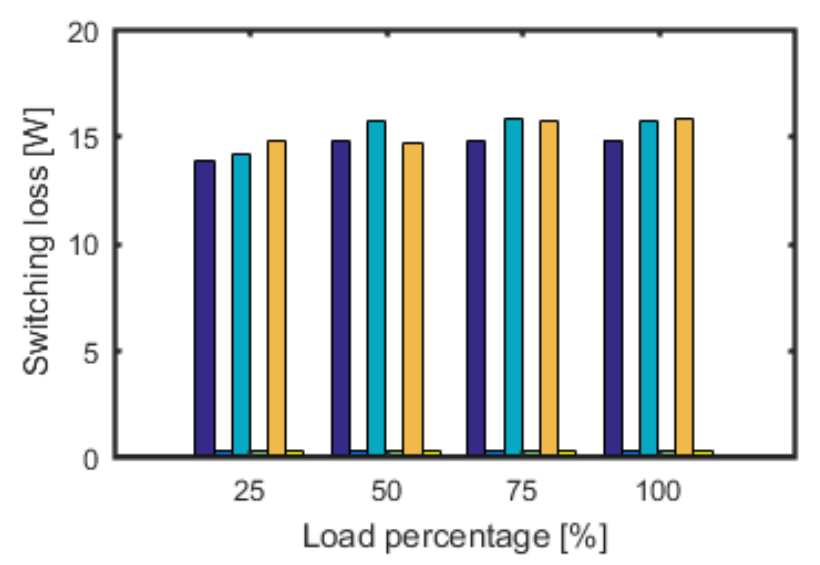

(b)

Figure 7. Comparison of the power device losses between the Si converters and $\mathrm{SiC}$ counterpart, at various load percentage and different operating modes (PV to EV, PV to BES, and BES to EV), (a) conduction losses, (b) switching losses with the same labels and orders as in (a).

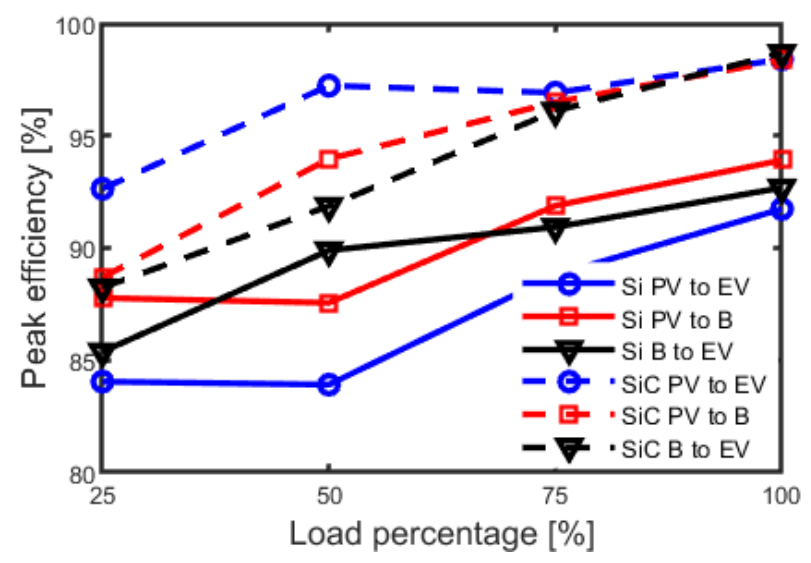

Figure 8. Comparison of the peak efficiency between the Si converters and $\mathrm{SiC}$ counterpart, at various load percentage and different operating modes (PV to $\mathrm{EV}, \mathrm{PV}$ to $\mathrm{BES}$, and $\mathrm{BES}$ to $\mathrm{EV})$.

developed to regulate the voltage sag, and balance the power gap between PV generation and EV charging demand. With the proposed control design, BES starts to discharge when PV is insufficient for local EV charging, and starts to charge when PV generation is surplus or power grid is at valley demand, such as during nighttime. As a result, the combination of EV charging, PV generation, and BES enhances the stability and reliability of the power grid. Different operating modes and their benefits are investigated and then, simulation and thermal models of the multiport converter based EV charging stations and the proposed SiC counterpart are developed in ANSYS TwinBuilder. Simulation results show that the efficiency can be improved by $5.67 \%, 4.46 \%$, and $6.00 \%$, respectively, for PV-to-EV mode, PV-to-BES, and BES-to-EV mode at nominal operating condition, compared to Si based EV charging stations under the same operating conditions.

\section{ACKNOWLEDGMENT}

The support of University of Kentucky, the L. Stanley Pigman endowment and the SPARK program, and of ANSYS Inc. is gratefully acknowledged.

\section{REFERENCES}

[1] V. Rallabandi, D. Lawhorn, J. He, and D. M. Ionel, "Current weakening control of coreless afpm motor drives for solar race cars with a threeport bi-directional dc/dc converter," in 2017 IEEE 6th International Conference on Renewable Energy Research and Applications (ICRERA), Nov 2017, pp. 739-744.

[2] Y. Liu, Y. Tang, J. Shi, X. Shi, J. Deng, and K. Gong, "Application of small-sized smes in an ev charging station with dc bus and pv system," IEEE Trans. on Applied Superconductivity, vol. 25, no. 3, pp. 1-6, June 2015.

[3] M. Ahmadi, N. Mithulananthan, and R. Sharma, "A review on topologies for fast charging stations for electric vehicles," in 2016 IEEE International Conference on Power System Technology (POWERCON), Sep. 2016, pp. 1-6.

[4] J. C. Mukherjee and A. Gupta, "A review of charge scheduling of electric vehicles in smart grid," IEEE Systems Journal, vol. 9, no. 4, pp. 15411553, Dec 2015.

[5] H. Zhu, D. Zhang, B. Zhang, and Z. Zhou, "A nonisolated three-port dcdc converter and three-domain control method for pv-battery power systems," IEEE Trans. on Industrial Electronics, vol. 62, no. 8, pp. 4937-4947, Aug 2015.

[6] A. Hassoune, M. Khafallah, A. Mesbahi, and T. Bouragba, "Smart topology of evs in a pv-grid system based charging station," in 2017 International Conference on Electrical and Information Technologies (ICEIT), Nov 2017, pp. 1-6.

[7] B. Honarjoo, S. M. Madani, M. Niroomand, and E. Adib, "Non-isolated high step-up three-port converter with single magnetic element for photovoltaic systems," IET Power Electronics, vol. 11, no. 13, pp. 21512160, 2018.

[8] S. Bai, D. Yu, and S. Lukic, "Optimum design of an ev/phev charging station with dc bus and storage system," in 2010 IEEE Energy Conversion Congress and Exposition, Sep. 2010, pp. 1178-1184.

[9] H. Zhu, D. Zhang, B. Zhang, and Z. Zhou, "A nonisolated three-port dcdc converter and three-domain control method for pv-battery power systems," IEEE Trans. on Industrial Electronics, vol. 62, no. 8, pp. 4937-4947, Aug 2015.

[10] H. Zhu, D. Zhang, Q. Liu, and Z. Zhou, "Three-port dc/dc converter with all ports current ripple cancellation using integrated magnetic technique," IEEE Trans. on Power Electronics, vol. 31, no. 3, pp. 2174-2186, March 2016.

[11] SunTech Power STP235-20-Wd, https://www.freecleansolar.com/ 235W-solar-panels-Suntech-STP235S-20-Wd-mono-p/stp235s-20-wd. htm, Accessed on 2018-12-19.

[12] CREE C3M0065090D MOSFET, https://www.wolfspeed.com/ c3m0065090d, Accessed on 2018-12-19.

[13] Infineon IPW90R120C3 MOSFET, https://www.infineon com/dgdl/Infineon-IPW90R120C3-DS-v01_00-en.pdf?fileId= db3a3043183a955501185000e1d254f2, Accessed on 2018-12-19. 